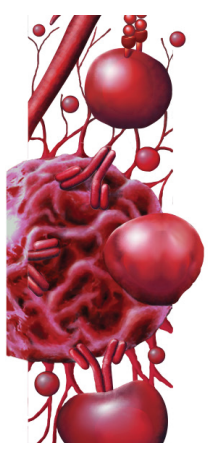

\title{
A review of allergoid immunotherapy: is cat allergy a suitable target?
}

To modify the course of allergy, different types of specific allergen immunotherapy have been developed such as sublingual immunotherapy and subcutaneous immunotherapy with native allergens or subcutaneous immunotherapy with polymerized allergoids. However, the optimal specific immunotherapy, especially for cat allergy, remains undetermined. Few studies investigating immunotherapy in cat allergy have been published, and the risk of serious adverse reactions and systemic reactions has often been an important issue. Monomeric allergoids have lower allergenic potential while their immunogenicity remains constant, resulting in excellent safety with notable efficacy. Specific immunotherapy with monomeric allergoids could, therefore, be of high value, especially in cat allergy as well as other types of allergy, and bring relief to a great community of patients.

First draft submitted: 18 September 2015; Accepted for publication: 16 December 2015; Published online: 10 February 2016

Keywords: allergoid $\bullet$ asthma $\bullet$ cat allergy $\bullet$ cat sensitization $\bullet$ rhinitis $\bullet$ SLIT $\bullet$ specific immunotherapy

\section{Background of cat allergy}

Sensitization to the major cat allergen Fel d 1 is one of the most frequent causes of persistent allergy. The prevalence of cat sensitization ranges up to $15 \%$ in some areas of northern Europe [1] and in many cases requires a multimodal therapeutic approach. Besides specific allergen immunotherapy (AIT), symptomatic treatment and avoidance of the allergen are recommended [2]. However, it is not always possible for patients to control cat allergy symptoms by removing the animal from the home and/or undergoing symptomatic therapy. This is due to the fact that Fel $\mathrm{d} 1$ particles are present at levels above the sensitization and asthma symptom thresholds ( $>1$ and $>8 \mu \mathrm{g} / \mathrm{g}$ ) even in homes that do not have indoor cats [3]. Wood et al. demonstrated that the removal of cats from homes did not necessarily coincide with the prompt reduction of cat allergen; on the contrary, high allergen levels persisted for at least another 5 months [4]. Custovic et al. showed that even though larger allergen particles of Fel d 1 were reduced for the most part 2 days after cat removal, smaller particles still remained after 14 days at $33 \%$ of baseline levels [5].

Interestingly, the prevalence of cat allergy homes before was $34 \%$, as reported by Ichikawa et al. [6]. On these grounds, it is essential to raise more awareness about specific AIT in cat allergy.

Worth particular mention is that cat allergy receives much interest among researchers and physicians. However, not many studies providing insight into cat allergy exist, and the ones that can be found are mostly out-of-date. There is not enough practical information on the treatment and line of action, which appears contradictory since many people suffer from this immunological disorder. in patients who had never kept cats in their
Nhung T Nguyen', Esther Raskopf ${ }^{1}$, Kija Shah-Hosseini', Gregor Zadoyan' \& Ralph Mösges*,1

IInstitute of Medical Statistics, Informatics \& Epidemiology (IMSIE), Faculty of Medicine, University of Cologne, Lindenburger Allee 42, 50931 Cologne, Germany *Author for correspondence: Tel.: +49221478 82929 Fax: +49 22147882940 ralph.moesges@uni-koeln.de
Future
Medicine fss 
Table 1. Polymerized allergoids: registered trade names and types of chemical modification.

\begin{tabular}{|ll|}
\hline Chemical modification & Polymerized allergoid examples \\
\hline Formaldehyde and $\mathrm{Al}(\mathrm{OH})_{3}$ & Allergovit, Acaroid \\
\hline Glutaraldehyde and tyrosine & Pollinex-R (Tyrosine-adsorbate) \\
\hline $\begin{array}{l}\text { Glutaraldehyde and tyrosine and monophosphoryl } \\
\text { lipid } \mathrm{A}(\mathrm{MPL})\end{array}$ & Pollinex Quattro \\
\hline Glutaraldehyde and $\mathrm{Al}(\mathrm{OH})_{3}$ & Purethal, Depigoid (depigmented allergoid) \\
\hline
\end{tabular}

\section{Conventional methods of allergen immunotherapy}

Sublingual immunotherapy (SLIT) with native allergens has been described to show clinical effects similar to those of subcutaneous immunotherapy (SCIT) [7-9]. No statistical differences between the SLITand SCIT-treated patients with respect to symptom and medication scores were found in a previous study [10].

The predominant benefit of noninvasive SLIT, however, is its better safety profile, which improves patients' acceptance and permits home administration, with no fatal events ever being reported unlike SCIT and with a lower risk of anaphylaxis [11]. Saporta et al. have even recommended that SLIT be regarded as first-choice therapy in asthmatic and young patients, considering that SCIT can be a risky choice. In their study, all the efficacy end points improved equally and significantly in both the SCIT and SLIT groups. But, because SLIT is reported to be safer, it should be favored over SCIT [12].

Despite the absence of fatal adverse events in SLIT with native allergens, many local and systemic reactions resulting in discomfort and therapy discontinuation have still been described [13-16]. In order to guarantee improved safety and greater convenience, modified allergens, such as allergoids, were brought into focus. Specific AIT with an allergoid could relieve allergic patients of their symptoms without involving a high risk of serious adverse reactions and fatalities.

Polymerized allergoids from the conventional perspective: efficient \& safe at the same time? There is a strong need to minimize the risk of fatalities and serious adverse reactions in AIT, especially from the patients' perspective. In order to meet this need, allergoids have been developed with the goal of making a substantial turn in AIT. An allergoid is defined as a chemically modified and potentiated allergen molecule. Through polymerization with glutaraldehyde or formaldehyde, a larger molecule is created to obtain better immunogenicity features and to strain out the allergenicity fractions of the allergen $[17,18]$.
A biochemical trial by Ibarrola et al. reported that polymerized allergoids exhibited an almost $100 \%$ lower IgE-binding potency than that of native allergens, while immunogenicity capacities were comparable for both AIT types [19].

Polymerized allergoids are currently used in longterm SCIT as well as short-term SCIT of a depot nature. Due to its large molecules, the allergoid dissolves more slowly, thereby maintaining its immunogenicity for a long period of time [20,21] (a summary of polymerized allergoids is provided in Table 1).

\section{Evidence of efficacy}

Many studies investigating polymerized allergoids suggest the strong positive impact of this AIT's efficacy [2224]. Gallego et al. reported that AIT with depigmented glutaraldehyde-modified allergens was very effective in treating allergies. After 1 year of therapy, a highly significant improvement of the total symptom score was achieved [25].

In one of the most recent studies, Roger $e t$ al. demonstrated that glutaraldehyde-modified allergoids for mite allergy significantly decreased nasal sensitivity and also significantly improved the symptom score [26].

Two studies have addressed the excellent efficacy with allergoids in children, reporting significant improvement of symptom and medication scores. These two studies have shown that this type of AIT is not only effective in adults, but also in younger patients [27,28].

Polymerized allergoids are very promising with respect to the improvement of clinical symptoms. However, there is still a downside to this form of therapy that is reflected in the safety aspect of polymerized allergoid immunotherapy.

Safety of polymerized allergoids - is it a further improvement compared with conventional SLIT or SCIT?

Despite the noteworthy efficacy results in almost all the studies considered in this review, the safety aspect needs to be viewed critically. In general, adverse reactions relating to the use of polymerized allergoids are not rare. A moderate number of patients often expe- 
rience local and systemic reactions [29,30]. Similar to these studies, an early study by Drachenberg et al. showed that the majority of actively treated patients experienced a local reaction, and many experienced a systemic reaction [31]. In a more recent study, RiekerSchwienbacher et al. reported that out of 48 patients, 23 patients had at least one local reaction, and 16 patients experienced at least one systemic adverse reaction [32]. Although many of the adverse reactions were of mild origin, from the patients' perspective, they could become a burden over time. Worth mentioning is also the study by Patel et al.: out of 135 patients treated with the tested allergoid, $>90 \%$ of the patients experienced at least one adverse reaction. Two percent were systemic reactions, and seven cases of the local adverse reactions were of severe intensity [33]. The matter of safety in allergoids should be emphasized, because allergoids were actually intended to be superior to SCIT with native allergens. For the most part, adverse events under SCIT with allergoids are not severe, yet a few studies reported serious adverse reactions or systemic reactions of a severe nature. Severe adverse reactions such as anaphylaxis were documented in three studies, one reaction of which required adrenalin rescue therapy and another one required prednisone therapy [28,34-35]. Besides the 'usual' local and systemic reactions to SCIT with allergoids, especially the impact on pulmonary function is to be considered. In general, asthmatic adverse reactions, wheezing and urticaria were reported in several studies that investigated the safety aspect [3641]. This ultimately led to the termination of the study for one of the patients due to an asthma attack following SCIT with an allergoid [42] (more detailed safety results from allergoid studies are presented in Table 2).

Therefore, it should be carefully considered whether polymerized allergoids offer a distinct advantage over conventional SCIT or SLIT. A medication intended to target allergic diseases but which itself commonly causes allergic complaints such as asthma, rhinitis, wheezing or urticaria would be counterproductive. Still, the injection route is obligatory and unavoidable when polymerized allergoids are applied. Thus, it is invasive, often painful and time-demanding for the patients [32]. Moreover, a large comparative study demonstrated that medication persistence under native SLIT was significantly higher than under native SCIT or allergoid SCIT, whereas no differences between the SCIT groups were observed [43]. These critical aspects surrounding polymerized allergoids can be seen as an appeal to find a new AIT mediator uniting all desirable features: a safe allergen that offers high immunogenicity potential and an easy route of application.

\section{Mechanism of action of carbamylated monomeric allergoids \& the benefits of monomeric allergoid SLIT over other AIT types} To ensure an even better safety profile than conventional SLIT, conventional SCIT or SCIT with polymerized allergoids, SLIT with monomeric allergoids may be a superior alternative. Pharmacokinetic studies with radiolabeled extracts speak in favor of a monomeric allergoid, which shows a higher plasma peak than the native allergen. In a study conducted by Bagnasco et al., the native allergen and the allergoid were radiolabeled with 123-Iodine to enable their measurements in blood plasma. The peak plasma concentration of the allergoid was significantly higher than that of the native allergen [44]. A monomeric allergoid possesses the same immunogenicity features but less allergenic potential: the IgE-binding sites are inactivated through carbamylation of the lysine group. Consequently, fewer therapy-related adverse events occur. All these characteristics are attained by selective chemical modification, thereby engineering a smaller molecule $(12-40 \mathrm{kDa})$ than that of conventional types of allergoids (e.g., through polymerization of the native allergen molecule). Hence, proper absorption of the monomeric allergoid into the oral mucosa is maintained. Thus, monomeric allergoid tablets are optimal for convenient sublingual intake in contrast to conventional allergoids, which always have to be administered subcutaneously $[11,45]$. The dose in which allergoid SLIT is administered is measured in allergic units (AU): the biological unit of SLIT with monomeric allergoids is defined as the unit that is equivalent to a fortieth of the mean provocative dose of the native allergen, according to the Summary of Product Characteristics.

\section{An introduction to the trials addressing the main} advantages of monomeric allergoids

Looking at the subject of monomeric allergoids in its entirety, not enough studies have been published so far, unlike studies concerning SLIT with native allergens. Yet, the advantages of SLIT with monomeric allergoids have been described in many studies since this agent for hyposensitization was launched.

In a randomized controlled trial, Ariano et al. clinically proved the reduced IgE-binding capacity through skin tests and specific IgE testing besides other improvements in symptom scores, medication scores and nasal provocation tests in the allergoid (from Arizona cypress pollen) group [46].

Another early randomized controlled trial of a monomeric allergoid for house dust mite allergy reported lower symptom scores in the active treatment group than in the placebo group. Also, merely one 
Table 2. Safety of allergoid subcutaneous immunotherapy: listing of studies addressing the safety aspect.

\begin{tabular}{|c|c|c|c|}
\hline Study (year) & $\begin{array}{l}\text { Polymerized allergoid type } \\
\text { modification }\end{array}$ & Safety and tolerability results & Ref. \\
\hline Klimek et al. (1999) & Formaldehyde $+\mathrm{Al}(\mathrm{OH})_{3}$ & $\begin{array}{l}79 \% \text { local reactions; } 12 \% \text { systemic reactions (including } \\
\text { rhinitis and asthma development) }\end{array}$ & [36] \\
\hline Negro et al. (1999) & Glutaraldehyde + tyrosine & $\begin{array}{l}15.5 \% \text { local reactions in } 404 \text { total injections; one patient } \\
\text { had asthma attack }\end{array}$ & [42] \\
\hline $\begin{array}{l}\text { Drachenberg et al. } \\
(2001)\end{array}$ & Glutaraldehyde + tyrosine & $\begin{array}{l}65 \text { of the } 81 \text { patients had at least one local reaction; } 14 \text { had } \\
\text { at least one systemic } A E\end{array}$ & [31] \\
\hline $\begin{array}{l}\text { Gietkiewicz et al. } \\
(2001)\end{array}$ & $\begin{array}{l}\text { Glutaraldehyde + tyrosine }+ \\
\text { monophosphoryl lipid A (MPL) }\end{array}$ & 'Few' local reactions; 1 systemic reaction out of 27 patients & [23] \\
\hline $\begin{array}{l}\text { Drachenberg et al. } \\
(2003)\end{array}$ & Glutaraldehyde + tyrosine & $\begin{array}{l}4.36 \% \text { AEs; six severe systemic reactions, of which one was } \\
\text { an anaphylactic reaction (prednisone required) }\end{array}$ & [34] \\
\hline $\begin{array}{l}\text { Drachenberg et al. } \\
(2003)^{\dagger}\end{array}$ & Glutaraldehyde + tyrosine & $25.9 \%$ local reactions, $2.2 \%$ systemic reactions & [27] \\
\hline Hansen et al. (2003) & Glutaraldehyde $+\mathrm{Al}(\mathrm{OH})_{3}$ & $15.2 \%$ local reactions; $4.3 \%$ systemic reactions & [39] \\
\hline Corrigan et al. (2005) & Formaldehyde $+\mathrm{Al}(\mathrm{OH})_{3}$ & $19.5 \%$ local reactions; $6.5 \%$ systemic reactions & [37] \\
\hline Dokic et al. (2005) & Formaldehyde $+\mathrm{Al}(\mathrm{OH})_{3}$ & $4.6 \%$ local reactions, no systemic reactions & [22] \\
\hline Keskin et al. (2006) ${ }^{\dagger}$ & Formaldehyde $+\mathrm{Al}(\mathrm{OH})_{3}$ & $\begin{array}{l}\text { 'Generally' local reactions; however, one patient had } \\
\text { anaphylaxis with adrenalin rescue, one had urticaria, one } \\
\text { had rhinoconjunctivitis }\end{array}$ & [28] \\
\hline $\begin{array}{l}\text { Bussmann et al., pilot } \\
(2007)\end{array}$ & Glutaraldehyde $+\mathrm{Al}(\mathrm{OH})_{3}$ & Two adverse reactions including eczema and asthma & [38] \\
\hline Williams et al. (2007) & Formaldehyde $+\mathrm{Al}(\mathrm{OH})_{3}$ & $\begin{array}{l}5.5 \% \text { local reactions; } 5 \text { of } 61 \text { patients }(82 \%) \text { had systemic } \\
\text { AEs including urticaria, wheezing and itching of eyes }\end{array}$ & [40] \\
\hline Gallego et al. (2010) & Glutaraldehyde $+\mathrm{Al}(\mathrm{OH})_{3}$ & Two local reactions in 27 patients $(7.4 \%)$ & {$[25]$} \\
\hline $\begin{array}{l}\text { Riechelmann et al. } \\
(2010)\end{array}$ & Glutaraldehyde $+\mathrm{Al}(\mathrm{OH})_{3}$ & $\begin{array}{l}20 \text { of } 66 \text { patients had at least one local reaction; } 6 \text { of } \\
66 \text { patients had at least one systemic reaction, one patient } \\
\text { developed rhinitis }\end{array}$ & [29] \\
\hline Rosewich et al. (2010) & $\begin{array}{l}\text { Glutaraldehyde + tyrosine }+ \\
\text { monophosphoryl lipid A (MPL) }\end{array}$ & $\begin{array}{l}30 \% \text { local reaction with two patients with local urticaria, } \\
\text { one patient had anaphylaxis + asthma + urticarial } \\
\text { (prednisone required) }\end{array}$ & [35] \\
\hline Gokmen et al. (2012) & Formaldehyde $+\mathrm{Al}(\mathrm{OH})_{3}$ & $\begin{array}{l}\text { Two systemic reactions: one had generalized urticaria } \\
+ \text { coughing + dyspnea, the other one only generalized } \\
\text { urticaria }\end{array}$ & {$[41]$} \\
\hline Pfaar et al. (2013) & Glutaraldehyde $+\mathrm{Al}(\mathrm{OH})_{3}$ & $\begin{array}{l}81 \text { out of } 144 \text { patients had a local reaction; } 14 \text { were } \\
\text { systemic reactions }\end{array}$ & [30] \\
\hline $\begin{array}{l}\text { Rieker- } \\
\text { Schwienbacher et al. } \\
(2013)\end{array}$ & Glutaraldehyde $+\mathrm{Al}(\mathrm{OH})_{3}$ & $\begin{array}{l}12 \% \text { local reaction and } 7 \% \text { systemic } A E \text { in } 440 \text { injections, } \\
\text { meaning } 59 \% \text { of patients had local AEs and } 41 \% \text { of the } \\
\text { patients had systemic AEs }\end{array}$ & [32] \\
\hline Patel et al. (2014) & $\begin{array}{l}\text { Glutaraldehyde + tyrosine + } \\
\text { monophosphoryl lipid A (MPL) }\end{array}$ & $\begin{array}{l}\text { More than } 90 \% \text { had at least one adverse reaction; }>2 \% \\
\text { had a systemic reaction; of the local reactions, seven were } \\
\text { severe }\end{array}$ & [33] \\
\hline
\end{tabular}

local adverse event (oral itching) that remained only for a few minutes after tablet intake was observed in the active group [47].

Several other studies have verified that SLIT with monomeric allergoid tablets shows significant improve- ment of clinical efficacy and safety in patients allergic to grass pollen, birch pollen and house dust mites. These improvements, along with the advantageous immunological changes, minimize the risk of side effects and fatalities, notably all with the absolute absence of 
severe adverse reactions [48-55]. A recent dose-response study demonstrated the safety of the tested monomeric allergoid, even at doses of $3000 \mathrm{AU}$ over the course of 1 year. In this trial, no serious adverse reactions were observed; only two patients had mild itchiness of the sublingual mucosa, and no dropouts were reported [56].

In a randomized controlled trial conducted by $\mathrm{La}$ Grutta et al., a monomeric allergoid for house dust mite allergy was compared with pharmacotherapy. A significant advantage of the allergoid over pharmacotherapy was observed, with greater reduction of the symptom score and of medication usage in the allergoid group [57].

In another comparative study, the visual analog scale results were significantly better in the two allergoid SLIT groups. The reduction in rescue medication use was also significantly greater in the $3000 \mathrm{AU}$ allergoid group than in the pharmacotherapy group. Furthermore, a significant decrease in bronchial reactivity (measured in a methacholine bronchial provocation test) was only observed in the allergoid SLIT groups [58].

Although monomeric allergoid tablets to treat cat allergy were introduced a long time ago, data exist almost only for pollen or house dust mite allergy. It is very important to mention this circumstance, because cat allergy can be highly critical due to the widespread presence of cat allergens, even in homes without cats. Thus, an observational study on the effectiveness and safety of cat monomeric allergoids opportunely provides notable results to add to the knowledge gained in the studies on cat allergy.

\section{Monomeric allergoid SLIT in cat-allergic patients: a viable solution in future treatments?}

Until now, it has been difficult to treat cat-allergic patients due to the risk of adverse reactions. However, SLIT with a monomeric allergoid may constitute a breakthrough. The Institute of Medical Statistics, Informatics and Epidemiology (IMSIE) conducted a retrospective, multicenter, observational survey of 70 cat-allergic patients who had undergone SLIT with carbamylated monomeric allergoid tablets. The survey was conducted from September 2013 to March 2014 and took into account a retrospective observation period from November 2006 to December 2013.

Patients who had been in therapy with monomeric allergoid tablets for at least 3 months were recruited anonymously from the physicians' practice populations. All patient data, also based on patients' records and information documentation, were collected anonymously from 21 practices across Germany. A questionnaire was designed to standardize the patient interviews that were performed by the investigators in their practices.

This observational survey was carried out to assess clinical effectiveness (disease severity improvement), safety and tolerability.

A current excerpt of results from an observational analysis showing improvement of clinical end

points

Out of the 70 patients diagnosed with cat allergy (through specific IgE testing), only 13 (18.6\%) were able to completely avoid contact with cats. The majority still had moderate to intense and sporadic to continuous exposure to cats. Among those who could not avoid the allergen, $29(41.4 \%)$ patients had daily to continuous exposure. Sixteen (22.8\%) out of 70 patients were allergic to other animal dander besides cat allergen.

All in all, significant clinical effectiveness, perceived as a shift of disease severity from one disease classification to a lower one, could be observed in all three allergic complaint groups (rhinitis, conjunctivitis and asthma) throughout the treatment years.

In the first year, almost a third (29.1\%) of the 55 rhinitis patients were symptom-free. Of the 36 rhinitis patients who remained in therapy in the second year, $52.8 \%$ had no symptoms. Of the ten remaining rhinitis patients in the third year, the majority $(80 \%)$ no longer had symptoms.

With respect to conjunctivitis in the first year, $35.6 \%$ of the 45 patients were symptom-free. In the second year, $55.2 \%$ of the remaining 29 conjunctivitis patients who were still in treatment had no symptoms, and $72.7 \%$ of 11 patients in the third year became symptom-free.

Of the 37 asthma patients in the first year, $35.1 \%$ patients became symptom-free. Of the 24 patients remaining in the second year, $58.3 \%$ had no asthma complaints. Finally, the majority $(70 \%)$ of the ten remaining patients who were in the third year of treatment had no complaints.

More than half $(54.3 \%)$ of the patients noticed the beginning of general symptom reduction during the first year, followed by symptom reduction onsets during initial therapy in $18.6 \%$ of patients. One individual reported an onset of symptom reduction during the second year, and five patients had not seen any responses (more details on clinical effectiveness are presented in Figures 1-3).

A subgroup analysis demonstrated the significant improvement of symptom severity classification in all three classified dosage regimens (regimen A: $2000 \mathrm{AU} /$ week, regimen B: 3000-6000 AU/week and regimen C: $7000 \mathrm{AU} /$ week) throughout the therapy phase. 
Regimen $\mathrm{C}$ was thereby significantly better than regimen $A$ in the second year $(p=0.015)$. A strong statistical tendency toward significance $(\mathrm{p}=0.051)$ was found in the second-year rhinitis patients for regimen $\mathrm{C}$ versus regimen $\mathrm{B}$, here also in favor of regimen $\mathrm{C}$. No statistical significance could be found among the rhinitis patients in the first year, conjunctivitis patients and asthma patients within these dosage regimen groups. An analysis for the third year is not meaningful due to the small number of patients.

Along with the excellent results on clinical effectiveness, compliance was found to be considerable as well. Out of 70 patients, $84.3 \%$ took their medication regularly, and $82.9 \%$ of the patients were always or mostly adherent with respect to check-ups and appointments, thereby showing considerable compliance.

Furthermore, a general decrease in medication usage was observed, with a significant reduction in the use of asthma medication $(\mathrm{p}<0.05)$ and antiallergic medication ( $\mathrm{p} \leq 0.001)$ after allergoid immunotherapy.

The survey showed that not only was the treatment effective, but it also illustrated the treatment's excellent safety: under therapy with carbamylated monomeric allergoid tablets, no cases of death, anaphylactic reactions, epinephrine use, serious adverse events or systemic adverse reactions were documented. Based on the World Allergy Organization (WAO) grading system for SLIT [61], only $10 \%$ of the patients experienced one local reaction each.

Nearly all patients rated the tolerability as 'excellent' or 'good' throughout the whole treatment period.

Finally, 51 out of 70 (72.9\%) individuals expressed great confidence and trust in the therapy with allergoid tablets. Fifty-two patients $(74.3 \%)$ indicated that they were highly motivated to continue allergoid therapy. Regarding practicality, out of 70 individuals, 48 patients (68.5\%) rated SLIT with monomeric allergoid tablets as 'very practical' or 'practical'. None of these individuals indicated that it was 'time-demanding' or 'very time-demanding'.

The analysis with sublingual monomeric allergoid tablets presented here was not intended to be a randomized controlled trial; thus, no control group was integrated. Also, it was not designed to make assumptions about the extent of efficacy of treatment with monomeric allergoid tablets. However, the analysis was meant to provide insight into how allergoid SLIT works within a practice routine environment. Furthermore, the transition of a majority of patients from persistent to intermittent allergic symptoms and from moderate/ severe to mild symptoms clearly marks a positive therapeutic effect, which is mirrored in the motivation rate, the numbers of satisfied patients and thus the therapeutic success as a whole. On these grounds, this survey is scientifically credible and provides substantial real-life evidence, which can aid clinical decision-making at the present or in the future.

\section{Role \& importance of carbamylated monomeric allergoids}

The surprising fact about monomeric allergoids, as gained from the current analysis, is that although a relevant number of patients with moderate-persistent asthma and a small number of patients with severe persistent asthma prior to SLIT were included, no serious adverse reactions were reported. Most studies share the view that concomitant, poorly controlled asthma is a high-risk factor for serious adverse reactions during SLIT [62]: this patient population is at a specific risk of developing pronounced adverse events, such as anaphylactic reactions and/or acute asthma attacks in extreme cases. This correlation was demonstrated in two case reports $[63,64]$. In another study, less severe adverse reactions such as wheezing were reported for asthmatic patients [65]. In our survey, however, none of these reactions occurred, demonstrating the very good safety profile of allergoid SLIT.

\section{Immunotherapy with monomeric allergoids - no trade-off in terms of safety}

First and foremost, it is necessary to emphasize that in all monomeric allergoid studies, no serious adverse events have ever occurred. Due to the advantageous characteristics of monomeric allergoids and their low-binding affinity to the IgE-binding site, local reactions of the mucosa have rarely been reported for tablets containing birch pollen or grass pollen allergoid $[66,67]$. In four other trials, monomeric allergoids were once more demonstrated to be particularly safe. In a dose-comparing study, extremely high doses of up to $14,000 \mathrm{AU}$ per week did not cause any severe adverse reactions. Only low-grade local and systemic reactions occurred [68]. In a very recent comparative dose-finding study (comparing weekly maintenance doses of 2100, 7000, 14,000 and 21,000 AU), significant results were observed for efficacy and safety. Importantly, enormous cumulative doses of up to 21,000 AU/week resulted in only very few local and systemic adverse reactions. There were no fatalities, no serious adverse reactions and no need for epinephrine. Moreover, more patients in the 14,000 AU group than in the groups taking the lower doses experienced improvements during conjunctival provocation. This observation denotes the excellent safety and tolerability of monomeric allergoid tablets, even at an uncommonly high maintenance dose [69].

Gammeri et al. performed ultra-rush allergoid therapy with pediatric and adult patients. Only one 
out of $105(0.9 \%)$ patients experienced a local adverse reaction. This study demonstrated the excellent safety profile of monomeric allergoid even applied as an ultrafast up-dosing regimen [70]. In another study, only two adverse reactions and no other complications were assessed during a shortened build-up induction phase. Once again, safety was maintained, and no adverse events were registered during maintenance therapy either [71].

This safety aspect was also confirmed in our catallergoid survey with as little as $10 \%$ total incidence of only local adverse reactions. This rate stands in stark contrast to that observed for conventional native-allergen SLIT (with almost 70\% incidence of local reactions in actively treated patients) [72] or to the $90 \%$ rate of adverse reactions reported in polymerized allergoidtreated patients [33]. The results from our recent observational survey mark a parallel to the findings from another study: in a postmarketing surveillance study previously mentioned in this paper, Lombardi et al. evaluated the safety of SLIT with monomeric allergoid tablets. Only 17 adverse events were reported in 198 patients total; no events were severe or fatal [54].

Safety is, besides symptom improvement and reduction of rescue medication use, the main argument needed to maintain the patient's trust throughout the whole therapy process. Only if safety is good, can compliance be ensured as well. Thus, as mentioned earlier in this paper, it is not only important to attain a safe treatment option for adult patients, but for pediatric patients even more so. Parents are often skeptical when it comes to medical treatments and do not want to compromise their children's safety. However, these worries are unjustified with regard to allergoid SLIT: among 36 pediatric patients, all under 5 years of age, only two adverse reactions occurred over a treatment course of 1-3 years [52]. This observation was confirmed in a subsequent trial: over 2 consecutive years, 12 -week preseasonal or coseasonal administration of a monomeric allergoid was shown to be safe with no adverse reactions reported [53].

\section{Evidence of clinical efficacy \& the carry-over effect of carbamylated monomeric allergoids} Another advantage of chemically modifying the respective allergen is the enhanced bioavailability, which in turn leads to improved clinical effects. Burastero et al. have proven that preseasonal and coseasonal SLIT regimens with birch monomeric allergoid tablets lead to greater efficacy. This trial reported that the symptom score improved by $30 \%$ and the use of antiallergic medication decreased by $40 \%$. For both end points, the improvements were significant when compared with the control group [73].

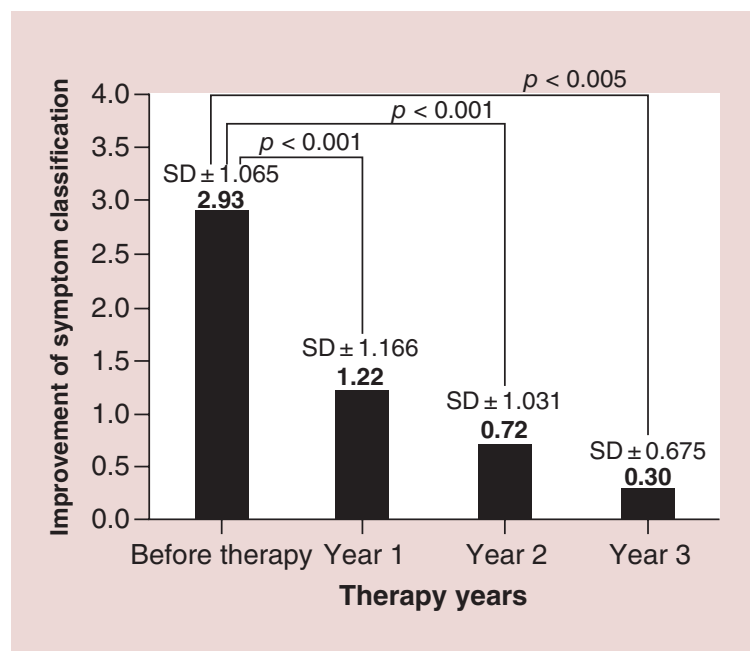

Figure 1. Rhinitis severity classification improvement. The improvement of disease severity and hence the shift from one disease severity classification to another was one of the primary end points. Rhinitis severity was classified according to the ARIA document as mild, moderate or severe, and as intermittent or persistent [59]. For rhinitis, 'no complaints' is defined as 0 , 'intermittent mild' as 1 , 'intermittent moderate/ severe' as 2, 'persistent mild' as 3 and 'persistent moderate/severe' as 4. Significant improvement of clinical effects: shifting of rhinitis severity classification (according to the ARIA document) from a mean of 2.93-1.22 ( $p<0.001)$ from baseline to first year, to $0.72(p<0.001)$ from baseline to second year, to 0.3 $(p<0.005)$ from baseline to third year. Although the $p$-values seem to increase in the third year of therapy, it is important to note that the number of patients remaining in the third year decreased, thus resulting in rising $p$-values. Nevertheless, all $p$-values are significant. ARIA: Allergic rhinitis and its impact on asthma

Very recently, Eichel et al. conducted a dose-finding trial with 154 patients who received one of four different weekly cumulative doses of birch pollen allergoid (2100, 4200, 7000 and 14,000 AU). Taking efficacy and safety together, the group with the $7000 \mathrm{AU}$ weekly cumulative dose had the best outcome, with a $70 \%$ improvement in the conjunctival provocation test and the most favorable safety outcome [74].

In a real-life setting, the analysis of cat-allergic patients has proven that not only the disease severity classification made a significant shift toward improvement, but also the medication score improved significantly. Altogether, a significant reduction of antiallergic medication could be achieved. Not only was the total number of intakes lower, but also the frequency of medication intake decreased. These results are supported by another study that showed significant reductions in medication use and allergic symptoms: in a placebo-controlled, randomized trial with grass pollen allergoid tablets, the symptom-medication score in the actively treated group was significantly lower 


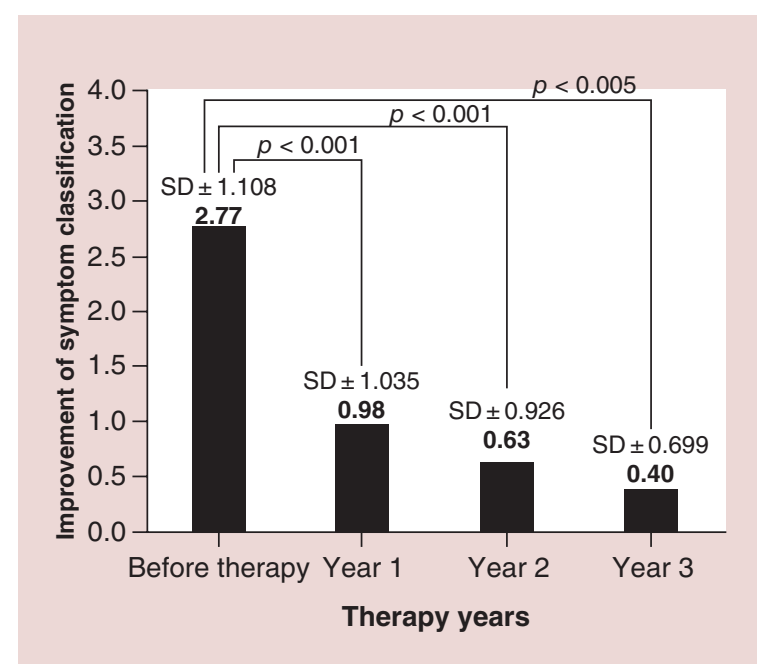

Figure 2. Conjunctivitis severity classification improvement. The improvement of disease severity and hence the shift from one disease severity classification to another was one of the primary end points. Conjunctivitis severity was classified according to the ARIA document as mild, moderate or severe, and as intermittent or persistent [59]. For conjunctivitis, 'no complaints' is defined as 0 , 'intermittent mild' as 1, 'intermittent moderate/severe' as 2, 'persistent mild' as 3 and 'persistent moderate/severe' as 4 . Significant improvement of clinical effects: shifting of conjunctivitis severity classification (according to the ARIA document) from a mean of 2.77-0.98 ( $p<0.001)$ from baseline to first year, to $0.63(p<0.001)$ from baseline to second year, to $0.4(p<0.005)$ from baseline to third year. Elevation of $p$-value due to a decrease of patient numbers in the third year. Although the $\mathrm{p}$-values seem to increase in the third year of therapy, it is important to note that the number of patients remaining in the third year decreased, thus resulting in rising $p$-values. Nevertheless, all p-values are significant.

than in the placebo group. Beyond that, all the children who underwent allergoid therapy experienced no adverse reactions at all [75]. Not only could the general decrease in the symptom or medication score be validated in several allergoid studies, but also skin test reactivity and nasal reactivity decreased during active testing $[28,76]$. Significantly, greater reduction of global symptom scores and skin test reactivity in the active treatment group (compared with pharmacotherapy) could also be demonstrated: compared with the pharmacotherapy group, there was only a nearly significant decrease in drug consumption in the allergoid group, but overall, the allergoid group showed better results in general and an excellent safety outcome [77].

Furthermore, another comparative study investigated the efficacy of preseasonal and coseasonal allergoid SLIT in contrast to pharmacotherapy. An elevation in the visual analog scale results was observed in both allergoid SLIT groups, but significant improve- ment could only be found in the coseasonal treatment group. With respect to rescue medication intake, significant improvement was recorded in the coseasonal allergoid group as well [78].

Through clinical studies, the efficacy of monomeric allergoid in comparison to placebo or pharmacotherapy could be evaluated for different therapy regimens and doses. However, what is even more interesting is the long-term potency of monomeric allergoids. Marogna et al. demonstrated in a long-term trial that under monomeric allergoid immunotherapy, major complaints such as allergic rhinitis and asthma decreased significantly among the SLIT allergoid patients when compared with the control group [79]. A few years later, Marogna et al. conducted another long-term study in which observations were made for up to 7-8 years after a 4-year monomeric allergoid immunotherapy had been completed. The goal was to evaluate the positive carryover and preventive effects of the monomeric allergoid sublingual immunotherapy within different therapy duration groups. The study demonstrated that patients who were treated the longest (4 years of allergoid SLIT) experienced the longest carryover effects until 8 years after the allergoid immunotherapy had ended. For all allergoid SLIT groups, significant clinical symptom reduction could be observed at least until the fourth to fifth year after completion of treatment [80].

The findings in these trials point out the potential of monomeric allergoids for modifying the course of many kinds of allergy. In these cases, monomeric allergoids have been proven to be a good choice to immediately treat allergic symptoms, to provide long-term treatment, to prevent the recurrence of allergies and also to work as a preventive agent.

\section{Highlights of studies involving monomeric allergoid-specific immunotherapy}

The major highlight is that treatment with carbamylated monomeric allergoids is safe and effective.

No fatalities and no serious adverse reactions have ever occurred during any of the studies that have been conducted by various researchers. Therapy-related adverse reactions were sporadically systemic and local, mostly of mild or local nature, even at maximum weekly cumulative doses of up to 21,000 AU. Even at this dose, monomeric allergoids have been proven to be safe. In very few trials, however, more adverse reactions occurred, although mostly of mild severity. This observation is most probably related to the fact that maintenance doses in these studies reached as high as 14,000 and 21,000 AU. However, these findings still certify the excellent safety of monomeric allergoids when compared with SCIT or SLIT with native aller- 
gens, or SCIT with polymerized allergoids. Supporting the safety aspect of monomeric allergoids, the trial by Lombardi et al. [54] reported only 17 adverse reactions in 198 patients. With respect to monomeric allergoids, not only were there fewer adverse reactions, but their intensity was weaker. It is noteworthy that not only do adults tolerate the different therapy regimens well, but also children and very young infants are not at risk when receiving allergoid SLIT.

The aspects of compliance and adherence have been slightly overlooked in these previous studies. Good compliance leads to therapy persistence and thus to therapy success. The issue of compliance with SLIT has already been pointed out in a paper emphasizing that only $7 \%$ of the patients treated with SLIT reached the minimal treatment duration time of 3 years, although SCIT adherence was not clearly higher [81]. This aspect needs to be investigated much more extensively in future allergoid studies and should be given more attention among prescribing physicians. More focus should be put on patient education and patient monitoring in order to reduce patients' anxiousness and thus to obtain better compliance results in allergoid SLIT.

Monomeric allergoids are relatively new in the field of sublingual-specific AIT; however, more randomized controlled trials and observational studies are needed to emphasize the strength and clinical benefits of monomeric allergoids. One of the main points worth exploring in the future should also be the long-term impact of allergoid SLIT, especially in larger patient collectives. It would also be interesting to analyze clinical end points of allergoid SLIT and compare them to conventional SLIT or SCIT in terms of efficacy. The superiority of monomeric allergoids to pharmacotherapy or placebo has already been highlighted in many studies [46-51,53,55,57-58,66-67,69,75,77-80]. What is needed is proof that allergoids are able to scientifically and medically replace conventional SLIT or SCIT in order to enable a safer, and hence, improved method for the patient's state of health and quality of life.

Last but not least, most of the trials focused on mites, grass pollen and birch pollen allergic patients. Only one trial [71] included one cat-allergic patient. This matter is critical since cat allergy is very common but often remains unnoticed. Hence, our analysis serves to fill the gap in this list of trials.

A collective listing of the trials and studies included in this review is found in Tables 3-5.

\section{The issue with cat allergy studies}

A further aspect that needs to be considered is whether specific AIT for cat allergy is effective in general.

So far, no observational study is available that evaluates the clinical effects, safety and tolerability of aller- goid SLIT exclusively in cat-allergic patients except the analysis with 70 cat-allergic patients.

However, several studies are available on SLIT with standardized native cat allergen extracts or synthetic peptides that provide evidence of its effectiveness. Sánchez Palacios et al. reported clinical effects and overall good tolerability in 20 patients who had received SLIT with natural cat dander extracts for 1 year [82]. In a randomized, placebo-controlled trial, Alvarez-Cuesta et al. reported a significant symptom reduction of $62 \%$ during the natural exposure challenge test and significant improvement of the peak expiratory flow in the actively treated group when compared with the placebo group, in which no changes occurred [83]. Addressing the need to cure cat allergy, several studies on synthetic cat peptide antigen have been conducted in recent years to demonstrate the clinical effects with this new method of hyposensitization [84]. Hafner et al. proved that synthetic cat peptides were significantly more effective than placebo [85].

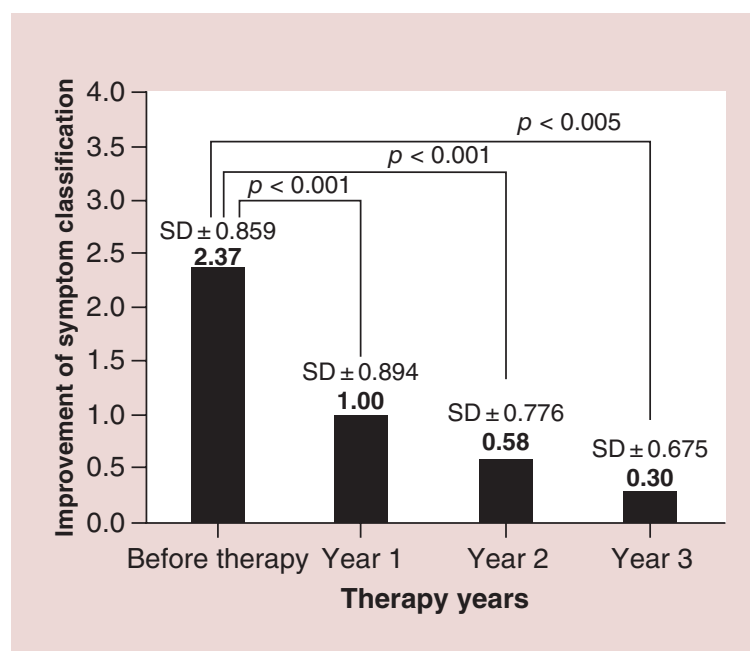

Figure 3. Asthma severity classification improvement. The improvement of disease severity and hence the shift from one disease severity classification to another was one of the primary end points. Asthma severity was rated according to the GINA guidelines [60]. For asthmatic patients, classification is labeled as 0 for 'no complaints', 1 for 'intermittent', 2 for 'mild persistent', 3 for 'moderate persistent' and 4 for 'severe persistent'. Significant improvement of clinical effects: shifting of asthma severity classification (according to the GINA guidelines) from a mean of 2.37-1.00 $(p<0.001)$ from baseline to first year, to $0.58(p<0.001)$ from baseline to second year, to $0.3(p<0.005)$ from baseline to third year. Elevation of $p$-value due to a decrease of patient numbers in the third year. Although the $p$-values seem to increase in the third year of therapy, it is important to note that the number of patients remaining in the third year decreased, thus resulting in rising $p$-values. Nevertheless, all $p$-values are significant. GINA: Global Initiative for Asthma. 


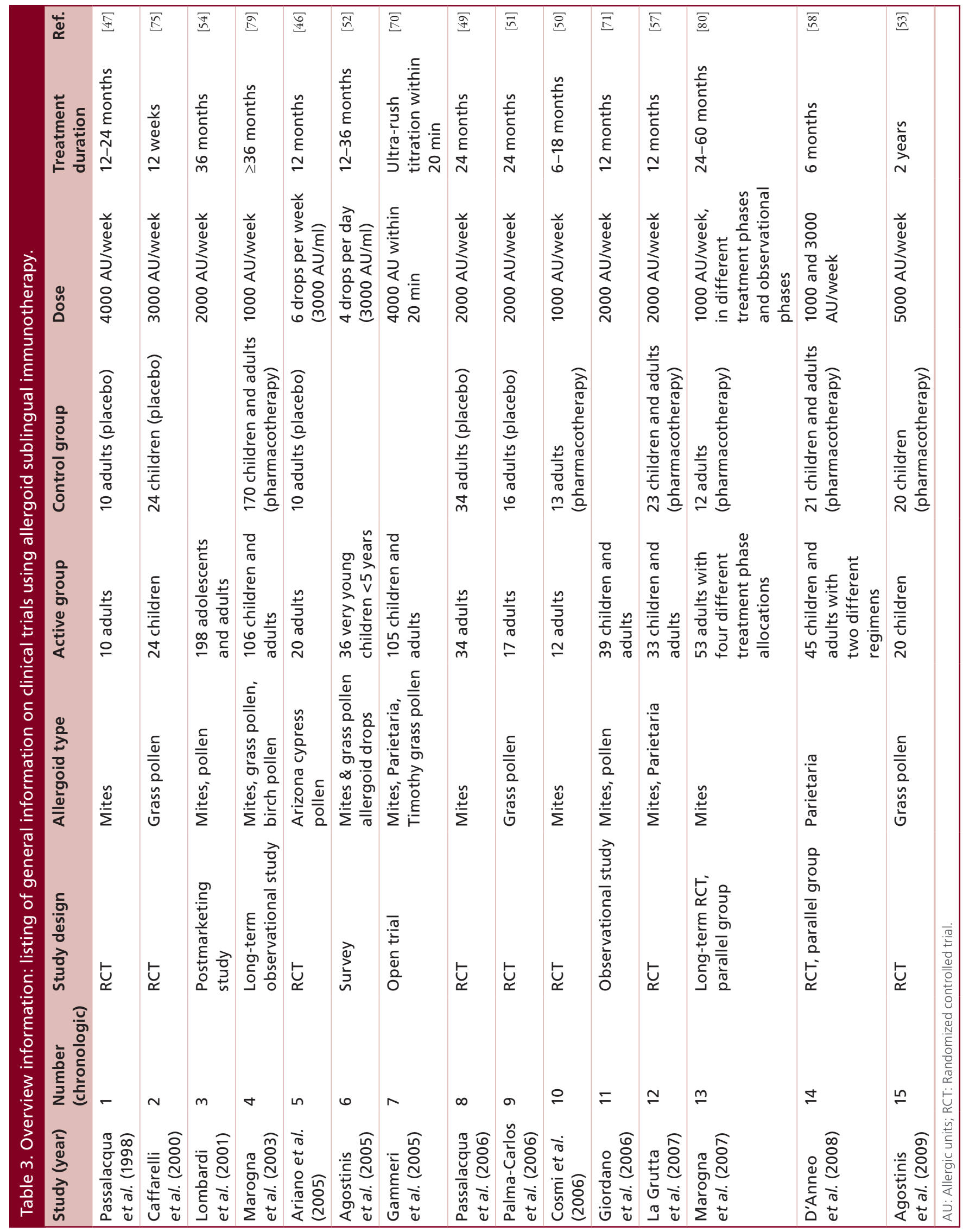




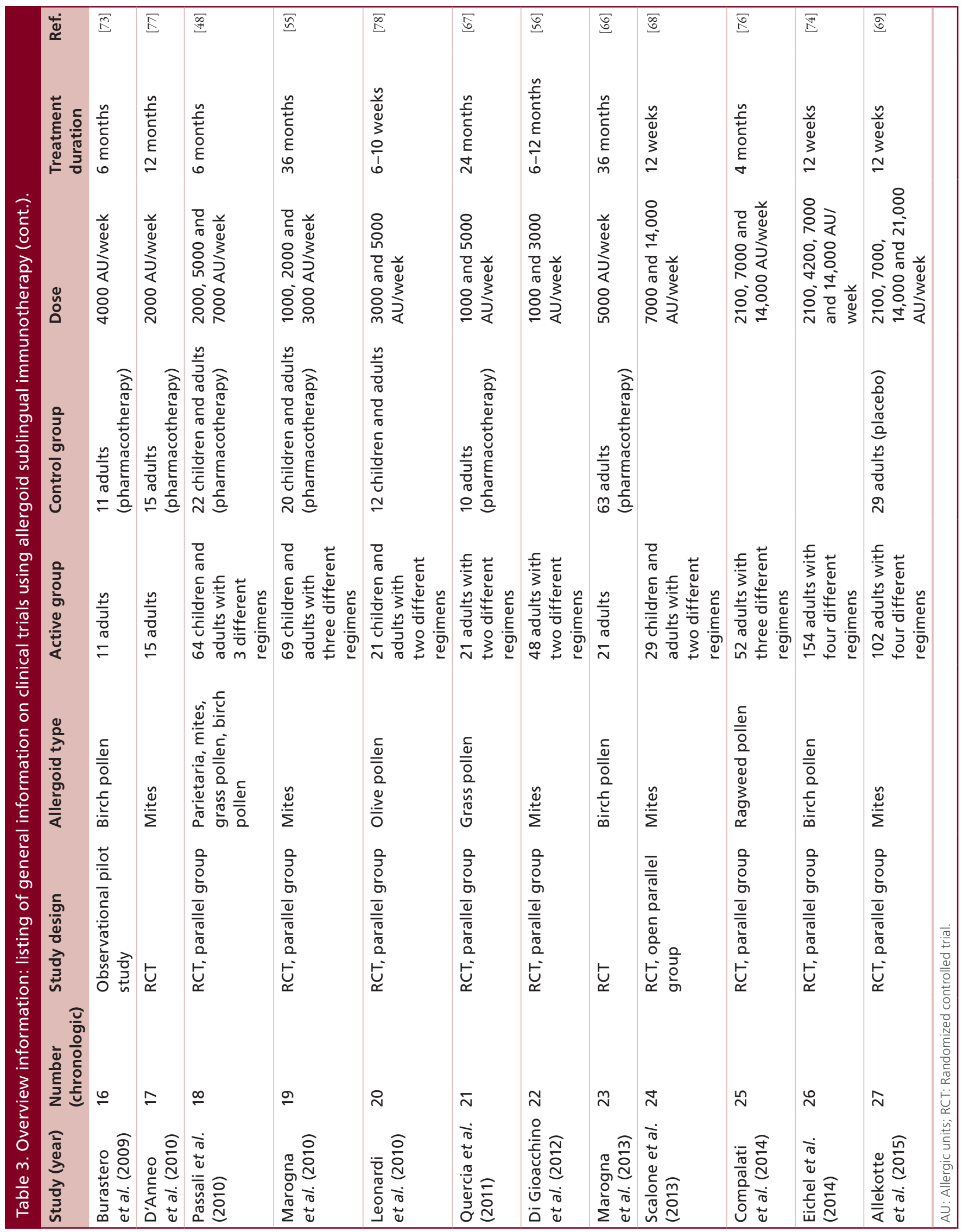




\begin{tabular}{|c|c|c|c|}
\hline Number & $\begin{array}{l}\text { Number of serious adverse } \\
\text { events in the treatment group }\end{array}$ & $\begin{array}{l}\text { Number of systemic adverse } \\
\text { events in the treatment group }\end{array}$ & $\begin{array}{l}\text { Number of local adverse } \\
\text { events in the treatment group }\end{array}$ \\
\hline 1 & 0 & 0 & 1 \\
\hline 2 & 0 & 0 & 0 \\
\hline 3 & 0 & 14 & 3 \\
\hline 4 & 0 & 0 & 2 \\
\hline 5 & 0 & 0 & 0 \\
\hline 6 & 0 & 0 & 2 \\
\hline 7 & 0 & 0 & 1 \\
\hline 8 & 0 & 0 & 3 \\
\hline 9 & 0 & 0 & 2 \\
\hline \multicolumn{4}{|l|}{10} \\
\hline 11 & 0 & 0 & 2 \\
\hline \multicolumn{4}{|l|}{12} \\
\hline \multicolumn{4}{|l|}{13} \\
\hline 14 & 0 & 0 & 0 \\
\hline 15 & 0 & 0 & 0 \\
\hline 16 & 0 & 0 & 2 \\
\hline 17 & 0 & 0 & 4 \\
\hline 18 & 0 & 0 & 6 \\
\hline 19 & 0 & 0 & 1 \\
\hline 20 & 0 & 0 & 0 \\
\hline 21 & 0 & 0 & 2 \\
\hline 22 & 0 & 0 & 2 \\
\hline 23 & 0 & 0 & 2 \\
\hline 24 & 0 & 22 & 1 \\
\hline 25 & 0 & 0 & 9 \\
\hline 26 & 0 & 44 & 20 \\
\hline 27 & 0 & 6 & 8 \\
\hline
\end{tabular}

As a result, our retrospective survey on SLIT with a monomeric allergoid for cat-allergic patients may support the clinical evidence on efficacy gained in these previous studies. Taking into account the often pronounced impact that cat allergy can have on a patient's quality of life and general well-being [86,87] as well as the potential of serious adverse reactions under treatment with nonmodified allergen extracts in cat allergy and other allergy types [88], SLIT with carbamylated monomeric allergoid tablets may be a viable alternative for the causal treatment of this chronic immunological disorder.

To specifically underline the risk factor of unmodified cat allergen extract for adverse events, a randomized placebo-controlled trial by Oppenheimer et al. should be mentioned at this point. This study, besides mentioning other adverse reactions, reported systemic adverse reactions such as pulmonary edema, persistent asthma and urticaria in the cat allergen group [89]. Even with synthetic cat allergen peptides, risks for serious and systemic adverse events exist. A placebocontrolled study, besides describing other adverse reactions, reported that three patients had experienced borderline serious adverse reactions and had undergone systemic epinephrine rescue therapy [90]. Additionally, a very recent trial addressing significant improvements of long-term effects with synthetic peptides reported systemic reactions such as bronchial spasm and a reduction of $\mathrm{FEV}_{1}$ (forced expiratory volume in $1 \mathrm{~s}$ ) [91]. 
Last but not least, it is important to stress the fact that it is usually difficult for the owner to remove a beloved pet from the home, an issue that can possibly be avoided if the allergic household member undergoes allergoid SLIT. On that account, SLIT with carbamylated monomeric allergoid tablets often does not

\begin{tabular}{|c|c|c|}
\hline Number & Symptom improvement & Medication improvement \\
\hline 1 & Symptom score: $\mathrm{p}<0.0002,48.4 \%$ & \\
\hline 2 & Symptom score: $p<0.05$ & $p<0.03$, after 8 weeks \\
\hline \multicolumn{3}{|l|}{3} \\
\hline 4 & $\mathrm{p}<0.001,84 \%$ & $\mathrm{p}<0.001,85.8 \%$ \\
\hline 5 & $\mathrm{p}<0.01$ after 1 year & $\begin{array}{l}p<0.01 \text { after } 1 \text { year; and significant improvement } \\
\text { toward placebo }(p<0.001)\end{array}$ \\
\hline \multicolumn{3}{|l|}{6} \\
\hline \multicolumn{3}{|l|}{7} \\
\hline 8 & Symptom score: $\mathrm{p}<0.027$, after 1 st year & $\mathrm{p}<0.036$, after 1 st year \\
\hline 9 & $\begin{array}{l}\text { After } 2 \text { years: } p<0.02 \text { (NPT), } p<0.02 \text { (conjunctivitis), } p<0.03 \\
\text { (rhinorrhea), } p<0.03 \text { (sneezing) }\end{array}$ & $p<0.02$ \\
\hline 10 & $\mathrm{p}<0.05$ & $\mathrm{p}<0.05$ \\
\hline \multirow[t]{2}{*}{11} & VAS: $52.7 \%$ & Mites: $p<0.001$ \\
\hline & & Pollen: $\mathrm{p}<0.01$ \\
\hline 12 & $\mathrm{p}<0.01$ & $\mathrm{p}<0.001$ \\
\hline 13 & $\begin{array}{l}\text { Symptom monthly score improvement in all four } \\
\text { groups: } p<0.001, p<0.027, p<0.001 \text { and } p<0.001\end{array}$ & \\
\hline 14 & VAS: $p<0.05$ for both active groups after 6 months & $p<0.05$ between 3 and 6 months for both groups \\
\hline 15 & Symptom score: $p=0.05$, VAS: $p<0.05$ after 1 st and 2 nd year & \\
\hline 16 & $p<0.0001,30 \%$ & $p<0.0001,40 \%$ \\
\hline 17 & Symptom score: $p<0.0004,52 \%$ VAS: $p<0.001,45 \%$ & $\begin{array}{l}\text { Nearly significant reduction of drug consumption } \\
\text { compared with control group, } p<0.059\end{array}$ \\
\hline 18 & $\mathrm{p}<0.02$ & $\mathrm{p}<0.02$ \\
\hline 19 & $\begin{array}{l}\text { Symptom score: } p<0.05(1000 \mathrm{AU}), \mathrm{p}<0.01(2000 \mathrm{AU}) \text { and } \\
p<0.001(3000 \mathrm{AU})\end{array}$ & $\begin{array}{l}p<0.05(1000 \mathrm{AU}), p<0.01(2000 \mathrm{AU}) \text { and } \\
p<0.001(3000 \mathrm{AU})\end{array}$ \\
\hline 20 & $\begin{array}{l}\text { VAS for both: } p<0.05 \text {; specific VAS improvement for } \\
5000 \mathrm{AU}: \mathrm{p}<0.01\end{array}$ & $5000 \mathrm{AU}$ regimen: $\mathrm{p}<0.05$ \\
\hline 21 & $\begin{array}{l}\text { VAS in both groups: } p<0.05 \text {, symptom score for both } \\
\text { groups: } p<0.05\end{array}$ & $p<0.05$ for both groups \\
\hline \multirow[t]{2}{*}{22} & Rhinitis: $p<0.05$ (3000 AU) & $p<0.05$ for both groups \\
\hline & VAS: $p<0.05(1000 \mathrm{AU}), \mathrm{p}<0.007$ (3000 AU) & \\
\hline 23 & $p<0.01(87 \%)$ & $\mathrm{p}<0.001$ \\
\hline 24 & NPT: in $100 \%$ of group 1, and in $93 \%$ of group 2 & \\
\hline 25 & $\begin{array}{l}p<0.0187 \text {, (statistical significance between } 300 \text { and } 2000 \text { AU } \\
\text { regimens) }\end{array}$ & \\
\hline 26 & $\begin{array}{l}\text { Symptom improvement in all groups in the conjunctival } \\
\text { provocation test after } 12 \text { weeks: } 78.9 \%(2100 \mathrm{AU}), 86.8 \% \\
(4200 \mathrm{AU}), 71.8 \%(7000 \mathrm{AU}) \text { and } 76.9 \%(14,000 \mathrm{AU})\end{array}$ & \\
\hline 27 & $\begin{array}{l}p=0.358,76.0 \%(21,000 \mathrm{AU}), p<0.05,88.5 \%(14,000 \mathrm{AU}) \\
p=0.358,76.0 \%(7000 \mathrm{AU}) \text { and } p=0.465,73.9 \%(2100 \mathrm{AU})\end{array}$ & \\
\hline
\end{tabular}


demand compromises in safety. Instead, it could provide long-term advantages and be a very safe way to cure cat allergy.

\section{Conclusion \& future perspective}

Very often clinicians are confronted with the question as to which therapy is best for their patients. One thing that needs to be emphasized is that SLIT is safe and shows high tolerability rates, especially in real-life settings [92].

Since 2010, the WAO has officially recommended SLIT as an effective treatment form for allergic rhinitis. More importantly, SLIT is recommended as a good alternative to SCIT based on its higher safety and adherence properties [93].

However, patients are the ones who will play an important role in choosing their therapy in the long run. From the psychological point of view, more and more patients will tend toward the method that is noninvasive, less time-consuming, more comfortable and safe. That realization inevitably turns our attention especially to allergoid SLIT. It is not only very safe with a much lower risk of fatalities; it also rarely causes systemic reactions in comparison to conventional SLIT.

The popularity of SCIT among prescribing physicians will likely decrease, because it requires too much time and effort from the patient with regard to the long therapy duration (at least 3 years). This was shown in a study by Huang et al:: reasons for discontinuation were the complex treatment process, adverse reactions, the long distance from the hospital and having no time for the treatment [94]. Although the duration factor could be minimized through the possibility of short-term SCIT regimens [95], the geographical inconvenience and the discomfort of invasive procedures remain the same. Nonetheless, SCIT is still prescribed more frequently than SLIT, although the development of AIT in the last decade indicates that the SLIT proportion among the prescribed AIT types is growing. The percentage of SLIT users increased from 2006 to 2012 from 8 to $29 \%$. On the contrary, the trend for SCIT decreased from 87 to $67 \%$ during the same time [96]. Because of the increase in the number of patients applying SLIT with native allergens, SLIT with an allergoid may also gain more acceptance and popularity among patients and prescribing doctors in the coming years, especially since it has far better safety and tolerability profiles. The use of a needle, serious adverse events, higher chances of systemic adverse reactions in SCIT and obligatory visits at the physician's practice could signify a major drawback for this patient collective. This is precisely the reason why allergoid SLIT is highly attractive for these individuals. Due to the excellent safety and tolerability of monomeric allergoids, the trend could increase toward allergoid SLIT for the difficult-to-treat cat allergy or other allergies that have previously received less attention.

Although SLIT has gained comprehensive acceptance and shows widespread usage among European physicians, the situation for SLIT in the USA is still difficult: because of many pending US FDA approvals for SLIT medications; SCIT remains the predominant AIT treatment form. Additionally, the financial aspect of SLIT and the little experience among American clinicians make it very difficult for SLIT to become more readily accepted [97]. Hence, the FDA first approved SLIT in the USA in 2014 [98]. Based on some of the existing FDA approvals of conventional SLIT medications, allergoid SLIT - exhibiting excellent safety and biochemical advantages - is likely to experience a comparatively faster breakthrough into the American field of AIT than conventional SLIT. However, more studies, particularly randomized controlled trials and longterm studies on allergoid SLIT, are needed in order to make this type of AIT more convincing, not only in Europe, but also in the USA and the rest of the world.

Based on the many notable results on efficacy and safety as well as a convenient user experience with allergoid SLIT, carbamylated monomeric allergoids could possibly become a main strategic pillar in the field of specific AIT.

\section{Authors' contributions}

The study was conceived by R Mösges. NT Nguyen, E Raskopf, G Zadoyan, K Shah-Hosseini and R Mösges participated in the design of the study. NT Nguyen collected the data for the study. NT Nguyen and K Shah-Hosseini carried out the study analysis and interpreted the data. NT Nguyen wrote the manuscript draft, and E Raskopf, G Zadoyan, K Shah-Hosseini and R Mösges made critical revisions. All authors reviewed, agreed to and approved the final manuscript.

\section{Acknowledgements}

We would like to express our deep gratitude to G Kittel for her valuable editorial assistance with this paper.

\section{Financial \& competing interests disclosure}

This study was sponsored by Lofarma Germany $\mathrm{GmbH}$, Willich, Germany. R Mösges received consulting fees from and/or conducted contract research for several companies including Lofarma Deutschland $\mathrm{GmbH}$. The authors have no other relevant affiliations or financial involvement with any organization or entity with a financial interest in or financial conflict with the subject matter or materials discussed in the manuscript apart from those disclosed.

No writing assistance was utilized in the production of this manuscript. 


\section{Cat allergy}

- Cat allergy is very common and frequently causes allergic rhinitis and asthma; treatment requires a multimodal approach with specific allergen immunotherapy as causal treatment.

Specific immunotherapy

- Many studies favor sublingual immunotherapy (SLIT) over subcutaneous immunotherapy as an effective, safe and convenient type of specific allergen immunotherapy.

- However, many systemic reactions are still observed under SLIT with native allergens; also, some studies have reported anaphylactic reactions.

Subcutaneous immunotherapy with polymerized monomeric allergoids

- There are different types of allergoids that are polymerized with glutaraldehyde or formaldehyde.

- Modified and polymerized allergoids are potentiated in their immunogenicity features, while allergenic potential is reduced.

- However, high rates of local and systemic adverse reactions have been reported.

- Results regarding adherence and medication persistence are not superior to those of SCIT with native allergens.

Sublingual immunotherapy with carbamylated monomeric allergoids

- SLIT with carbamylated monomeric allergoids is an advantage due to the biochemistry and pharmacokinetics of this type of allergoid.

- Monomeric allergoids have a lower molecular weight than polymerized allergoids; thus, they can be well absorbed into the oral mucosa.

- Carbamylated monomeric allergoids still possess the same immunological potency, but the IgE-binding positions are inactivated, thus the allergenic reactions and adverse events can be minimized.

- Many randomized controlled trials have proven effectiveness of monomeric allergoids that is superior to placebo or pharmacotherapy.

- All in all, monomeric allergoids are safe, clinically effective, and show preventive long-term benefits.

Results from a survey of $\mathbf{7 0}$ cat-allergic patients treated with allergoids

- Severity of allergic rhinitis, conjunctivitis and asthma improved significantly.

- More than half of the patients experienced an onset of improvement during an early stage of therapy (the first year of therapy).

- Significant reduction of antiallergic and asthma medication use.

- Under therapy with monomeric allergoid tablets there were no cases of death, no anaphylactic reactions, no use of epinephrine, no other serious adverse events and no systemic adverse reactions.

- Seven patients $(10 \%)$ reported only one local adverse reaction each, and the majority rated tolerability as excellent.

- The majority of patients rated this form of immunotherapy as practical, and patients were highly motivated to continue the therapy.

\section{References}

Papers of special note have been highlighted as: • of interest; •- of considerable interest

1 Plaschke P, Janson C, Norman E et al. Skin prick test and specific $\operatorname{IgE}$ in adults from three different areas of Sweden. Allergy 51(7), 461-472 (1996).

2 Heutelbeck AR. [Prevention of allergic airways diseases due to cat allergens]. Article in German. Allergo J. 14(3), 190-197 (2005).

3 Arbes SJ Jr, Cohn RD, Yin M, Muilenberg ML, Friedmann W, Zeldin DC. Dog allergen (Can f 1) and cat allergen (Fel d 1) in US homes: results from the National Survey of Lead and Allergens in Housing. J. Allergy Clin. Immunol. 114(1), 111-117 (2004)

4 Wood RA, Chapman MD, Adkinson NF Jr, Eggleston PA. The effect of cat removal on allergen content in household-dust samples. J. Allergy Clin. Immunol. 83(4), 730-734 (1989).

5 Custovic A, Simpson A, Pahdi H, Green RM, Chapman MD, Woodcock A. Distribution, aerodynamic characteristics, and removal of the major cat allergen Fel d 1 in British homes. Thorax 53(1), 33-38 (1998).

6 Ichikawa K, Iwasaki E, Baba M, Chapman MD. High prevalence of sensitization to cat allergen among Japanese children with asthma, living without cats. Clin. Exp. Allergy 29(6), 754-761 (1999).

7 Mauro M, Russello M, Incorvaia C, Gazzola GB, Di Cara G, Frati F. Comparison of efficacy, safety and immunologic effects of subcutaneous and sublingual immunotherapy in birch pollinosis: a randomized study. Eur. Ann. Allergy Clin. Immunol. 39(4), 119-122 (2007).

8 Antúnez C, Mayorga C, Corzo JL, Jurado A, Torres MJ. Two year follow-up of immunological response in miteallergic children treated with sublingual immunotherapy. Comparison with subcutaneous administration. Pediatr. Allergy Immunol. 19(3), 210-218 (2008).

9 Eifan AO, Akkoc T, Yildiz A et al. Clinical efficacy and immunological mechanisms of sublingual and subcutaneous immunotherapy in asthmatic/rhinitis children sensitized to 
house dust mite: an open randomized controlled trial. Clin. Exp. Allergy 40 (6), 922-932 (2010).

10 Khinchi MS, Poulsen LK, Carat F, André C, Hansen AB, Malling HJ. Clinical efficacy of sublingual and subcutaneous birch pollen allergen-specific immunotherapy: a randomized, placebo-controlled, double-blind, double-dummy study. Allergy 59(1), 45-53 (2004).

11 Compalati E, Braido F, Canonica GW. Sublingual immunotherapy: recent advances. Allergol. Int. 62(4), 415-423 (2013).

12 Saporta D. Efficacy of sublingual immunotherapy versus subcutaneous injection immunotherapy in allergic patients. J. Environ. Public Health 2012, 492405 (2012).

13 Windom HH, Lockey RF. An update on the safety of specific immunotherapy. Curr. Opin. Allergy Clin. Immunol. 8(6), 571-576 (2008).

14 Lin SY, Erekosima N, Kim JM et al. Sublingual immunotherapy for the treatment of allergic rhinoconjunctivitis and asthma: a systematic review. JAMA 309(12), 1278-1288 (2013).

15 Cox LS, Larenas Linnemann D, Nolte H, Weldon D, Finegold I, Nelson HS. Sublingual immunotherapy: a comprehensive review. J. Allergy Clin. Immunol. 117(5), 1021-1035 (2006)

16 André C, Vatrinet C, Galvain S, Carat E, Sicard H. Safety of sublingual-swallow immunotherapy in children and adults. Int. Arch. Allergy Immunol. 121(3), 229-234 (2000).

17 Fernandez-Caldaz E, Zakzuk J, Lockey RF. Disease summaries. Allergen standardization and characterization (2009). www.worldallergy.org

18 Klimek L, Thorn C, Pfaar O. Depigmentierte Allergoide für die allergenspezifische Immuntherapie. In: $H N O$ 2010 (Volume 58). Springer Medizin Verlag, Heidelberg, Germany, 51-56 (2009).

19 Ibarrola I, Sanz ML, Gamboa M et al. Biological characterization of glutaraldehyde-modified parietaria judaica pollen extracts. Clin. Exp. Allergy 34(2), 303-309 (2004).

20 Rosewich M, Lee D, Zielen S. Pollinex Quattro: an innovative four injections immunotherapy in allergic rhinitis. Hum. Vaccin. Immunother. 9(7), 1523-1531 (2013).

21 Trautmann A. Saisonale/intermittierende Rhinitis allergica. In: Allergiediagnose, Allergietherapie: 75 Tabellen. Thieme Verlag, Stuttgart, Germany, 43 (2006).

22 Dokic D, Schnitker J, Narkus A, Cromwell O, Frank E. Clinical effects of specific immunotherapy: a two-year double-blind, placebo-controlled study with a one year follow-up. Prilozi 26(2), 113-129 (2005).

23 Gietkiewicz K, Fal AM, Malolepszy J. [Evaluation of effectiveness and safety of three year immunotherapy with mixed grass pollen allergens]. Article in Polish. Pol. Arch. Med. Wewn. 106(6), 1163-1168 (2001).

24 von Baehr V, Hermes A, von Baehr R et al. Allergoid-specific T-cell reaction as a measure of immunological response to specific immunotherapy (SIT) with a Th1-adjuvanted allergy vaccine. J. Invest. Allergol. Clin. Immunol. 15(4), 234-241 (2005).
25 Gallego MT, Iraola V, Himly M et al. Depigmented and polymerized house dust mite allergoid: allergen content, induction of IgG4 and clinical response. Int. Arch. Allergy Immunol. 153(1), 61-69 (2010).

26 Roger A, Depreux N, Jurgens Y, Heath MD, Garcia G, Skinner MA. A novel and well tolerated mite allergoid subcutaneous immunotherapy: evidence of clinical and immunologic efficacy. Immun. Inflamm. Dis. 2(2), 92-98 (2014).

27 Drachenberg KJ, Heinzkill M, Urban E, Woroniecki SR. Efficacy and tolerability of short-term specific immunotherapy with pollen allergoids adjuvanted by monophosphoryl lipid A (MPL) for children and adolescents. Allergol. Immunopathol. 31(5), 270-277 (2003).

28 Keskin O, Tuncer A, Adaliogly G, Sekerel BE, Sackesen $\mathrm{C}$, Kalayci O. The effects of grass pollen allergoid immunotherapy on clinical and immunological parameters in children with allergic rhinitis. Pediatr. Allergy Immunol. 17(6), 396-407 (2006).

29 Riechelmann H, Schmutzhard J, van der Werf JF, Distler A, Kleinjans HA. Efficacy and safety of a glutaraldehydemodified house dust mite extract in allergic rhinitis. Am. J. Rhinol. Allergy 24(5), 104-109 (2010).

30 Pfaar O, van Twuijver E, Hecker H, Boot JD, van Ree R, Klimek L. Accelerated up-dosing of subcutaneous immunotherapy with a registered allergoid grass pollen preparation. Int. Arch. Allergy Immunol. 160(4), 420-424 (2013).

31 Drachenberg KJ, Wheeler AW, Stuebner P, Horak F. A well-tolerated grass pollen-specific allergy vaccine containing a novel adjuvant, monophosphoryl lipid $\mathrm{A}$, reduces allergic symptoms after only four preseasonal injections. Allergy 56(6), 498-505 (2001).

32 Rieker-Schwienbacher J, Nell MJ, Diamant $Z$ et al. Openlabel parallel dose tolerability study of three subcutaneous immunotherapy regimens in house dust mite allergic patients. Clin. Transl. Allergy 3(1), 16 (2013).

33 Patel P, Holdich T, Drachenberg KJ, Huber B. Efficacy of a short course of specific immunotherapy in patients with allergic rhinoconjunctivitis to ragweed pollen. J. Allergy Clin. Immunol. 133(1), 121-129 (2014).

34 Drachenberg KJ, Pröll S, Urban E, Woroniecki SR. Singlecourse specific immunotherapy with mixed pollenallergoids: results of a multi-center study. Allergol. Immunopathol. 31(2), 77-82 (2003).

35 Rosewich M, Schulze J, Eickmeier O et al. Tolerance induction after specific immunotherapy with pollen allergoids adjuvanted by monophosphoryl lipid A in children. Clin. Exp. Immunol. 160(3), 403-410 (2010).

36 Klimek L, Dormann D, Jarman ER, Cromwell O, Riechelmann H, Reske-Kunz AB. Short-term preseasonal birch pollen allergoid immunotherapy influences symptoms, specific nasal provocation and cytokine levels in nasal secretions, but not peripheral T-cell responses, in patients with allergic rhinitis. Clin. Exp. Allergy 29(10), 1326-1335 (1999).

37 Corrigan CJ, Kettner J, Doemer C, Cromwell O, Narkus A. Efficacy and Safety of preseasonal-specific immunotherapy 
with an aluminium-adsorbed six-grass pollen allergoid. Allergy 60(6), 801-807 (2005).

ussmann C, Maintz L, Hart J et al. Clinical improvemen and immunological changes in atopic dermatitis patients undergoing subcutaneous immunotherapy with a house dust mite allergoid: a pilot study. Clin. Exp. Allergy 37(9), 1277-1285 (2007).

39 Hansen I, Hörmann K, Stuck BA, Schneider-Gene S, Mösges R, Klimek L. Cluster-immunotherapy in seasonal allergic rhinitis: safety aspects of induction therapy with depot allergoids(Purethal). Laryngorhinootologie 82(8), 558-563 (2003). benefit of a third year of specific grass pollen allergoid immunotherapy in patients with seasonal allergic rhinitis. Eur. Ann. Allergy Clin. Immunol. 39(4), 123-126 (2007).

41 Gokmen NM, Ersoy R, Gulbahar O et al. Desensitization Effect of preseasonal seven-injection allergoid immunotherapy with olive pollen on basophil activation: the efficacy of olive pollen-specific preseasonal allergoid immunotherapy on basophils. Int. Arch. Allergy Immunol. 159(1), 75-82 (2012)

42 Negro JM, Wheeler AW, Hernandez J et al. Comparison of the efficacy and safety of two preseasonal regimens of glutaraldehyde modified, tyrosine-adsorbed parietaria pollen extract over a period of three years in monosensitive patients. Allergol. Immunopathol. (Madr.) 27(3), 153-164 (1999).

43 Sieber J, De Geest S, Shah-Hosseini K, Mösges R. Medication persistence with long-term, specific grass pollen immunotherapy measured by prescription renewal rates. Curr. Med. Res. Opin. 27(4), 855-861 (2011).

- Reports that medication persistence rates are better for sublingual immunotherapy (SLIT) than for subcutaneous immunotherapy (SCIT) with native allergens and for SCIT with polymerized allergoids.

44 Bagnasco M, Passalacqua G, Villa G et al. Pharmacokinetics of an allergen and a monomeric allergoid for oromucosal immunotherapy in allergic volunteers. Clin. Exp. Allergy 31(1), 54-60 (2001).

45 Mösges R, Ritter B, Kayoko G, Allekotte S. Carbamylated monomeric allergoids as a therapeutic option for sublingual immunotherapy of dust mite- and grass pollen-induced allergic rhinoconjunctivitis: a systematic review of published trials with a meta-analysis of treatment using Lais ${ }^{\circledR}$ tablets. Acta. Dermatovenerol. Alp. Pannonica Adriat. 19(3), 3-10 (2010).

46 Ariano R, Panzani RC, Mistrello G. Efficacy of sublingual coseasonal immunotherapy with a monomeric allergoid in Cupressaceae pollen allergy. Eur. Ann. Allergy Clin. Immunol. 37(3), 103-108 (2005).

47 Passalacqua G, Albano M, Fregonese L et al. Randomized controlled trial of local allergoid immunotherapy on allergic inflammation in mite-induced rhinoconjunctivitis. Lancet 351(9103), 629-632 (1998).

48 Passali D, Mösges R, Passali GC, Passali FM, Ayoko G, Bellussi L. Safety, tolerability and efficacy of sublingual allergoid immunotherapy with three different shortened updosing administration schedules. Acta. Otorhinolaryngol. Ital. 30(3), 131-137 (2010).
49 Passalacqua G, Pasquali M, Ariano R et al. Randomized double-blind controlled study with sublingual carbamylated allergoid immunotherapy in mild rhinitis due to mites. Allergy 61(7), 849-854 (2006).

50 Cosmi L, Santarlasci V, Angeli R et al. Sublingual immunotherapy with Dermatophagoides monomeric allergoid down-regulates allergen-specific immunoglobulin $\mathrm{E}$ and increases both interferon-gamma- and interleukin-10production. Clin. Exp. Allergy 36(3), 261-272 (2006).

51 Palma-Carlos AG, Santos AS, Branco-Ferreira M et al. Clinical efficacy and safety of preseasonal sublingual immunotherapy with grass pollen carbamylated allergoid in rhinitic patients. A double-blind, placebo-controlled study. Allergol. Immunopathol. (Madr.) 34(5), 194-198 (2006).

52 Agostinis F, Tellarini L, Canonica GW, Falagiani P, Passalacqua G. Safety of sublingual immunotherapy with a monomeric allergoid in very young children. Allergy 60(1), 133 (2005).

- Monomeric allergoids are also very safe for very young children under 5 years. Monomeric allergoids promise to fulfill safety and efficacy criteria.

53 Agostinis F, Foglia C, Bruno ME, Falagiani P. Efficacy, safety and tolerability of sublingual monomeric allergoid in tablets given without up-dosing to pediatric patients with allergic rhinitis and/or asthma due to grass pollen. Eur. Ann. Allergy Clin. Immunol. 41(6), 177-180 (2009).

54 Lombardi C, Gargioni S, Melchiorre A et al. Safety of sublingual immunotherapy with monomeric allergoid in adults: multicenter post-marketing surveillance study. Allergy 56(10), 989-992 (2001).

55 Marogna M, Colombo F, Cerra C et al. The clinical efficacy of a sublingual monomeric allergoid at different maintenance doses: a randomized controlled trial. Int. J. Immunopathol. Pharmacol. 23(3), 937-945 (2010).

56 Di Gioacchino M, Cavallucci E, Ballone E et al. Dosedependent clinical and immunological efficacy of sublingual immunotherapy with mite monomeric allergoid. Int. J. Immunopathol. Pharmacol. 25(3), 671-679 (2012).

57 La Grutta S, Arena A, D'Anneo WR et al. Evaluation of the antiinflammatory and clinical effect of sublingual immunotherapy with carbamylated allergoid in allergic asthma with or without rhinitis. A 12-month perspective, randomized, controlled trial. Ann. Allergy Clin. Immunol. 39(2), 40-44 (2007).

58 D'Anneo WR, Arena A, Gammeri E et al. Parietaria sublingual allergoid immunotherapy with a co-seasonal treatment schedule. Allergol. Immunopathol. 36(2), 79-84 (2008).

59 Bousquet J, Schünemann HJ, Samolinski B et al. Allergic rhinitis and its impact on asthma (ARIA): achievement in 10 years and future needs. J. Allergy Clin. Immunol. 130(5), 1049-1062 (2012).

60 GINA Report. Global strategy for asthma management and prevention. Revised 2006. www.ginasthma.org

61 Canonica GW, Cox L, Pawankar R et al. Sublingual immunotherapy: World Allergy Organization position paper 2013 update. World Allergy Organ. J. 7(1), 6 (2014). 
62 Calderón MA, Simons FE, Malling HJ et al. Sublingual allergen immunotherapy: mode of action and its relationship with the safety profile. Allergy 67(3), 302-311 (2012).

- The use of SLIT in patients with severe-persistent asthma could pose a high risk for developing adverse events.

63 Antico A, Pagani M, Crema A. Anaphylaxis by latex sublingual immunotherapy. Allergy 61(10), 1236-1237 (2006).

64 Scala G, Ciccarelli A, Calabrò C. Adverse reaction to sublingual Parietaria vaccine following an ultra-rush induction. Eur. Ann. Allergy Clin. Immunol. 46(3), 116-118 (2014).

65 Pajno GB, Peroni DG, Vita D, Pietrobelli A, Parmiani S, Boner AL. Safety of sublingual immunotherapy in children with asthma. Paediatr. Drugs 5(11), 777-781 (2003).

66 Marogna M, Braidi C, Bruno ME et al. The contribution of sublingual immunotherapy to the achievement of control in birch-related mild persistent asthma: a real-life randomised trial. Allergol. Immunopathol. (Madr.) 41(4), 216-224 (2013).

67 Quercia O, Bruno ME, Compalati E et al. Efficacy and safety of sublingual immunotherapy with grass monomeric allergoid: comparison between two different treatment regimens. Eur. Ann. Allergy Clin. Immunol. 43(6), 176-183 (2011).

68 Scalone G, Compalati E, Bruno ME, Mistrello G. Effect of two doses of carbamylated allergoid extract of dust mite on nasal activity. Eur. Ann. Allergy Clin. Immunol. 45(6) 193-200 (2013).

- Even at unusually high doses up to $14,000 \mathrm{AU} /$ week, no serious adverse reactions were reported with monomeric allergoids. Only low-grade local and systemic reactions occurred.

69 Allekotte S, Hüser C, Dieterich P, Singh J, Compalati MD, Mösges R. A randomized Dpbc dose-finding trial of SLIT allergoid tablets in house dust mites (HDM) allergic patients. J. Allergy Clin. Immunol. 135(2), Abstract L24. (2015).

- Only local and systemic AEs at doses up to 21,000 AU/ week were reported. No serious AEs occurred.

70 Gammeri E, Arena A, D'Anneo R, La Grutta S. Safety and tolerability of ultra-rush (20 minutes) allergoid sublingual immunotherapy in patients with allergic rhinitis and/or asthma. Allergol. Immunopathol. (Madr.) 33(3), 142-144 (2005).

71 Giordano T, Quarta C, Bruno ME, Falagiani P, Riva G. Safety, tolerability and efficacy of sublingual allergoid immunotherapy with a 4-day shortened build-up phase. Eur. Ann. Allergy Clin. Immunol. 38(9), 310-312 (2006).

72 Didier A, Malling HJ, Worm M et al. Optimal dose, efficacy, and safety of once-daily sublingual immunotherapy with a 5 -grass pollen tablet for seasonal allergic rhinitis. J. Allergy Clin. Immunol. 120(6), 1338-1345 (2007).

73 Burastero SE, Mistrello G, Paolucci C et al. Clinical and immunological correlates of pre-co-seasonal sublingual immunotherapy with birch monomeric allergoid in patients with allergic rhinoconjunctivitis. Int. J. Immunopathol. Pharmacol. 22(2), 343-352 (2009).
74 Eichel A, Düster M, Astvatsatourov A, Shah-Hosseini K, Mösges R. Efficacy of birch pollen allergoid sublingual tablets for the treatment of AR: a prospective, randomised, controlled, double-blind dose-finding study in 154 patients. EAACI PosterAbstract 771 (2014).

75 Caffarelli C, Sensi LG, Marucci F, Cavagni G. Preseasonal local allergoid immunotherapy to grass pollen in children: a double-blind, placebo-controlled, randomized trial. Allergy 55(12), 1142-1147 (2000).

76 Compalati E, Ortolani C, Pastorello E et al. Poster 1000: efficacy and safety of specific sublingual immunotherapy with carbamylated allergoid tablets of ragweed pollen: a dose-ranging study. World Allergy Organ. J. 7(Suppl. 1), P1 (2014).

77 D'Anneo RW, Bruno ME, Falagiani P. Sublingual allergoid immunotherapy: a new 4-day induction phase in patients allergic to house dust mites. Int. J. Immunopathol. Pharmacol. 23(2), 553-560 (2010).

78 Leonardi S, Arena A, Bruno ME et al. Olea sublingual allergoid immunotherapy administered with two different treatment regimens. Allergy Asthma Proc. 31(2), 25-29 (2010).

79 Marogna M, Massola A. Sublingual immunotherapy in the context of a clinical practice improvement program in the allergological setting: results of a long-term observational study. Eur. Ann. Allergy Clin. Immunol. 35(4), 133-140 (2003).

80 Marogna M, Bruno M, Massolo A, Falagiani P. Long-lasting effects of sublingual immunotherapy for house dust mites in allergic rhinitis with bronchial hyperreactivity: a long-term (13-year) retrospective study in real life. Int. Arch. Allergy Immunol. 142(1), 70-78 (2007).

- The long-term carryover effect proves the potency of monomeric allergoids. They are not only safe and effective in acute treatment, but they also work as a preventive measure in the long run.

81 Kiel MA, Röder E, Gerth van Wijk R, Al MJ, Hop WC, Rutten-van Mölken MP. Real-life compliance and persistence among users of subcutaneous and sublingual allergen immunotherapy. J. Allergy Clin. Immunol. 132(2), 353-360 (2013).

82 Sánchez Palacios A, Schamann F, García JA. [Sublingual immunotherapy with cat epithelial extract. Personal experience]. Article in Spanish. Allergol. Immunopathol. (Madr.) 29(2), 60-65 (2001).

83 Alvarez-Cuesta E, Berges-Gimeno P, González-Mancebo E, Fernández-Caldas E, Cuesta-Herranz J, Casanovas M. Sublingual immunotherapy with a standardized cat dander extract: evaluation of efficacy in a double blind placebo controlled study. Allergy 62 (7), 810-817 (2007).

84 Patel D, Couroux P, Hickey P, Salapatek A et al. Fel d 1-derived peptide antigen desensitization shows a persistent treatment effect 1 year after the start of dosing: a randomized placebo controlled study. J. Allergy Clin. Immunol. 131(1), 103-109 (2013).

85 Hafner RP, Patel P, Salapatek A, Laidler P, Larche M, Patel D. Fel d 1 peptide antigen desensitization safety and efficacy in a double-blind, placebo-controlled environmental 
exposure chamber study. World Allergy Organ. J. 6(1), 150 (2013).

Everhart RS, Kopel SJ, Esteban CA et al. Allergic rhinitis quality of life in urban children with asthma. Ann. Allergy Asthma Immunol. 112(4), 365-370 (2014).

87 González-Núñez V, Valero AL, Mullol J. Impact of sleep as a specific marker of quality of life in allergic rhinitis. Curr. Allergy Asthma Rep. 13(2), 131-141 (2013).

RE, Bush RK, Peden D, Lockey RF. Sublingual-oral administration of standardized allergic extracts: Phase 1 safety and dosing results. Ann. Allergy Asthma Immunol. 100(5), 475-481 (2008).

89 Oppenheimer J, Areson JG, Nelson HS. Safety and efficacy of oral immunotherapy with standardized cat extract. J. Allergy Clin. Immunol. 93(1), 61-67 (1994).

90 Maguire P, Nicodemus C, Robinson D, Aaronson D, Umetsu DT. The safety and efficacy of ALLERVAX CAT in cat allergic patients. Clin. Immunol. 93(3), 222-231 (1999).

91 Couroux P, Patel D, Armstrong K, Larche M, Hafner RP. Fel d 1-derived synthetic peptide immuno-regulatory epitopes show a long-term treatment effect in cat allergic subjects. Clin. Exp. Allergy. 45(5), 974-978 (2015).

92

Senna G, Caminati M, Canonica GW. Safety and tolerability of sublingual immunotherapy in clinical trials and real life. Curr. Opin. Allergy Clin. Immunol. 13(6), 656-662 (2013).
93 Aboshady OA, Elghanam KM. Sublingual immunotherapy in allergic rhinitis: efficacy, safety, adherence and guidelines. Clin. Exp. Otorhinolaryngol. 7(4), 241-249 (2014).

94 Huang YN, Huang Y, Dai JH, Yang FF. Causes of stopping subcutaneous specific immunotherapy in asthmatic children. Zhongguo Dang Dai Er Ke Za Zhi. 14(9), 671-674 (2012).

95 Claes C, Mittendorf T, Graf von der Schulenburg JM. Persistence and frequency of prescriptions of subcutaneous allergen-specific immunotherapy (SCIT) prescribed within the German statutory health insurance. Med. Klin. (Munich) 104(7), 536-542 (2009).

96 McDonell AL, Wahn U, Demuth D et al. Allergy immunotherapy prescribing trends for grass pollen-induced allergic rhinitis in Germany: a retrospective cohort analysis. Allergy Asthma Clin. Immunol. 11(1), 19 (2015).

- During the last decade, the proportion of patients applying SLIT grew while SCIT user numbers decreased.

97 Elenburg S, Blaiss MS. Current status of sublingual immunotherapy in the United States. World Allergy Organ. J. 7(1), 24 (2014).

98 'FDA approves first sublingual allergen extract for the treatment of certain grass pollen allergies.' www.fda.gov 